\title{
Role of hypoxia-inducible factor-1 $\alpha$ in autophagic cell death in microglial cells induced by hypoxia
}

\author{
XINTAO WANG $^{1 *}$, JUN MA $^{1 *}$, QIANG FU ${ }^{1 *}$, LEI ZHU ${ }^{1}$, \\ ZHILING ZHANG ${ }^{2}$, FAN ZHANG ${ }^{1}$, NAN LU ${ }^{1}$ and AIMIN CHEN ${ }^{1}$ \\ ${ }^{1}$ Department of Orthopedic Trauma Surgery, Changzheng Hospital, The Second Military Medical University, Shanghai 200003; \\ ${ }^{2}$ Department of Orthopedic Surgery, Chinese People's Liberation Army 425th Hospital, Sanya, Hainan 572000, P.R. China
}

Received November 26, 2015; Accepted December 1, 2016

DOI: $10.3892 / \mathrm{mmr} .2017 .6277$

\begin{abstract}
Microglial cells are phagocytic cells of the central nervous system (CNS) and have been proposed to be a primary component of the innate immune response and maintain efficient CNS homeostasis. Microglial cells are activated during various phases of tissue repair and participate in various pathological conditions in the CNS. Following spinal cord injury (SCI), anoxemia is a key problem that results in tissue destruction. Hypoxia-inducible factor $1-\alpha(\mathrm{HIF}-1 \alpha)$ may protect hypoxic cells from apoptosis or necrosis under ischemic and anoxic conditions. However, numerous studies have revealed that hypoxia upregulates HIF-1 $\alpha$ expression leading to the death of microglial cells. The present study investigated the alterations in HIF-1 $\alpha$ expression levels and the mechanism of autophagic cell death mediated by HIF-1 $\alpha$ in microglial cells induced by hypoxia. Hypoxia was demonstrated to induce HIF-1 $\alpha$ expression and autophagic cell death in microglial cells. Enhanced autophagy reduced cell death during the initial stages by restraining the functions of autophagy-associated genes (microtubule-associated protein 1A/1B-light chain 3 phosphatidylethanolamine conjugate and Beclin-1) and modulating the expression of inflammatory cytokines (tumor necrosis factor- $\alpha$ and interleukin-1 $\beta$ ). Target value was determined by Cell Counting Kit 8 and cell death by flow cytometry. Transmission electron microscopy, immunohistochemical staining, reverse transcription-quantitative polymerase chain reaction, western blotting, and ELISA were used for further analysis. However, increased expression
\end{abstract}

Correspondence to: Professor Aimin Chen, Department of Orthopedic Trauma Surgery, Changzheng Hospital, The Second Military Medical University, 415 Fengyang Road, Shanghai 200003, P.R. China

E-mail: aiminchen@aliyun.com

*Contributed equally

Key words: hypoxia inducible factor- $1 \alpha$, hypoxia, autophagic cell death, microtubule-associated protein 1A/1B-light chain 3 phosphatidylethanolamine conjugate, beclin-1, BV2 cells of HIF-1 $\alpha$ induced cell death and autophagic cell death in microglial cells. Furthermore, the effects of the HIF-1 $\alpha$ inhibitor 2-methoxyestradiol and HIF-1 $\alpha$ small interfering RNA on the death and autophagy of microglial cells in vitro were investigated. These investigations revealed the suppression of autophagy, the decrease of cell viability and the increase of inflammatory cytokines results from HIF-1 $\alpha$ inhibition or HIF-1 $\alpha$ silencing. In conclusion, the results indicated that appropriate expression of HIF-1 $\alpha$ can ameliorate autophagic cell death of microglial cells associated with hypoxia, and may provide a novel therapeutic approach for SCI associated with microglial cell activation.

\section{Introduction}

Spinal cord injury (SCI) involves a complex sequence of pathological processes consisting of original injury, secondary lesion and spinal restoration (1). SCI is associated with severe neurological outcomes and limited therapeutic options are available. The pathogenesis of SCI involves altered blood circulation, abnormal distribution of bioactive substances and production of free radicals (2). Anoxemia following the development of SCI leads to tissue destruction, and results in a variety of vascular pathologies resulting in acute arterial occlusion, surgical interventions requiring clamping, trauma-causing ischemia, transplantation, and shock (2-4).

Microglial cells are resident immune cells of the central nervous system (CNS) that continuously survey the environment and respond to alterations in cellular homeostasis resulting from infection, hypoxia, stroke, and other stimuli. It has previously been demonstrated that activated microglial cells initiate neuronal and oligodendrocyte injury and exacerbate a variety of neurological conditions by secreting pro-inflammatory molecules including nitric oxide, tumor necrosis factor-alpha (TNF- $\alpha$ ), and interleukin-1 $\beta$ (IL-1 $\beta$ ) (5-7). Inflammation is important in protecting the CNS from infection, and directly or indirectly controls the sequelae of SCI. The release of inflammatory cytokines and chemokines from spinal cord cells in or near the lesion initiates the inflammatory response in the CNS $(8,9)$.

Hypoxia-inducible factor 1 (HIF-1) is an important regulator under conditions of hypoxia (10) and is also important in controlling the neurological outcomes following ischemic 
stroke due to its ability to regulate a variety of genes (11). HIF-1 $\alpha$ is degraded in cells under normoxic conditions, however is significantly upregulated during hypoxia. The accumulation of HIF-1 $\alpha$ is important in stimulating angiogenesis, glycolysis and erythropoiesis by upregulating the expression of downstream target genes, which are involved in cellular tolerance to hypoxia and tissue vascularity, thus helping the injured tissue to heal (12). However, various studies have revealed that hypoxia may not only directly damage neurons but may promote neuronal injury indirectly via activation of microglial cells via the regulation of HIF-1 $\alpha$ during cerebral ischemia $(13,14)$.

Autophagy is an intracellular catabolic pathway, which degrades cell components, toxic aggregates and damaged organelles, and recycles them as basic building blocks for the efficient maintenance of cellular homeostasis (15). Autophagy is important for the elimination of pathogens and production of cytokines from macrophages $(16,17)$. Autophagy controls inflammation through interactions with immune signaling pathways and regulates the secretion of molecular mediators of inflammation $(18,19)$. An appropriate level of autophagy contributes to neuroprotection, whereas inappropriate levels may induce cell death $(20,21)$.

Therefore, it was hypothesized that HIF-1 $\alpha$ regulation of autophagy is important in microglial cells during SCI. However, the formation and regulation of autophagy in microglial cells, and its effect on the production of pro-inflammatory and cytotoxic factors under conditions of hypoxia remain to be elucidated. The present study investigated the relationship and mechanism of action of HIF-1 $\alpha$ and autophagy in microglial cells during the development of SCI.

\section{Materials and methods}

Reagents and antibodies. High glucose Dulbecco's modified Eagle's medium (DMEM/H-G) was purchased from Hyclone Laboratories; GE Healthcare Life Sciences (Logan, UT, USA). Fetal bovine serum (FBS) was purchased from Gibco; Thermo Fisher Scientific, Inc. (Waltham, MA, USA). The 4',6-diamidino-2-phenylindole (DAPI) $0.25 \%$ trypsin-EDTA, Cell Counting Kit (CCK-8), protein extraction kit including radioimmunoprecipitation assay buffer (RIPA), and bicinchoninic acid (BCA) protein assay kit were purchased from Beyotime Institute of Biotechnology (Haimen, China). Dimethyl sulfoxide (DMSO) and bovine serum albumin (BSA) were purchased from Biosharp Biotechnology Co. (Hefei, China). 2-Methoxyestradiol (2ME2) was purchased from Selleck Chemicals (Houston, TX, USA). Antibodies against HIF-1 $\alpha$ (cat. no. ab179483), microtubule-associated protein 1A/1B-light chain 3 (LC-3) phosphatidylethanolamine conjugate (LC3-II) (cat. no. ab51520), and Beclin-1 (cat. no. ab207612) were obtained from Abcam (Cambridge, UK). Antibodies against $\beta$-actin (cat. no. GB13001-3), and tetramethylrhodamine (TRITC)-conjugated secondary antibody (cat. no. 111-095-003) were obtained from Sevicebio Technology (Wuhan, China).

Isolation of spinal microglial cells. Spinal microglial cells were isolated by Percoll density gradient centrifugation as previously described (22). A total of 20 intact male 1-day old mice were provided by the animal experimental center of The Second Military Medical University (Shanghai, China). Uniform commercial diets were purchased from the animal experimental center of The Second Military Medical University (Shanghai, China). Mice were housed individually with feed and tap water available ad libitum at $25^{\circ} \mathrm{C}$ and $70 \%$ humidity under a 12/12 h light/dark cycle and were sacrificed by $\mathrm{CO}_{2}$ asphyxia. Mice were placed into a box in which euthanasia took place, the box was made of glass and had a volume of $181(23 \times 26 \times 33 \mathrm{~cm})$. A rising concentration of $\mathrm{CO}_{2}$ was released into the cage by a tube at a rate of $3.6 \mathrm{l} / \mathrm{min}$, the final concentration of $\mathrm{CO}_{2}$ was $100 \%$. The time taken to observe loss of consciousness and respiratory arrest of mice was at least $5 \mathrm{~min}$ both in the cage and out of the cage. Lumbar enlargements of the spinal cords of 1-day old mice were digested with $0.1 \%$ trypsin. The study was approved by the ethics committee of the Second Military Medical University (Shanghai, China; no. 13071002124). Spinal cords were ground briefly in $4 \mathrm{ml}$ ice-cold Hanks, balanced salt solution (Beyotime Institute of Biotechnology, Haimen, China) and filtered through a nylon mesh (200 mesh; $74 \mu \mathrm{m})$ to remove astrocytes and undigested tissue. The cells were seeded into flasks coated with poly-L-lysine and cultured with DMEM supplemented with $10 \% \mathrm{FBS}$ at $37^{\circ} \mathrm{C}$ with $5 \% \mathrm{CO}_{2}$. Culture media were replenished twice per week for 2 weeks. Microglial cells were detached by gentle shaking on a horizontal shaker at $120 \mathrm{rpm}$ for $3 \mathrm{~h}$ at $37^{\circ} \mathrm{C}$, centrifuged at $800 \times g$ for $10 \mathrm{~min}$ at $20^{\circ} \mathrm{C}$, then resuspended in fresh DMEM supplemented with 10\% FBS and plated at a final density of $5 \times 10^{5}$ cells $/ \mathrm{ml}$ in a six-well culture plate at $37^{\circ} \mathrm{C}$ with $5 \% \mathrm{CO}_{2}$. The cell purity was determined by immunohistochemical (IHC) staining using microglial cell specific antibody CD11b (cat. no. ab75476; rabbit against rat and mouse; 1:100; Abcam). The microglial cell cultures used were $>95 \%$ pure.

BV2 cell culture and hypoxic conditions of microglial cells. Due to the limited number of primary culture cells available, BV2 cells were used as substitute for the studies of hypoxia-induced mechanisms in microglial cells, where stated. BV2 cells were obtained from the Department of Neurobiology, Second Military Medical University (Shanghai, China). BV2 cells were cultured in DMEM/H-G supplemented with $10 \%$ FBS, $50 \mathrm{U} / 1$ penicillin and $50 \mathrm{mg} / \mathrm{ml}$ streptomycin at $37^{\circ} \mathrm{C}$ in a humidified atmosphere incubator containing $5 \%$ $\mathrm{CO}_{2}$. BV2 is an immortalized microglial cell line that has been reported to share numerous characteristics exhibited by primary microglial cells $(23,24)$.

For exposure to hypoxic conditions, the culture medium was replaced, followed by appropriate treatment prior to cell exposure to hypoxia in a chamber, containing a $1 \% \mathrm{O}_{2} / 5 \%$ $\mathrm{CO}_{2} / 94 \% \mathrm{~N}_{2}$ gas mixture for the indicated time period. BV2 cells were pretreated with $3 \mu \mathrm{M} 2 \mathrm{ME} 2$ or transfected with $50 \mathrm{nM}$ HIF-1 $\alpha$ siRNA prior to exposure to hypoxia.

Inhibitor and small interfering (si)RNA treatment. Cells were exposed to the HIF-1 $\alpha$ inhibitor 2ME2 to determine the mechanisms of hypoxia-induced autophagy. BV2 cells were seeded in six-well plates and pretreated with $3 \mu \mathrm{M} 2 \mathrm{ME} 2$ for $6 \mathrm{~h}$ prior to hypoxia exposure. These pretreated BV2 cells were exposed to hypoxia for 3, 6, 9, 12 and $24 \mathrm{~h}$. Supernatants 
from cell cultures were collected and assayed for secreted cytokines, and cell pellets were used for RNA isolation and reverse transcription-quantitative polymerase chain reaction (RT-qPCR) analysis. For transfection with siRNA, cells were plated in six-well plates at $5 \times 10^{5}$ cells/well. Plated cells were grown in DMEM supplemented with $10 \%$ FBS overnight, and transfected with $50 \mathrm{nM}$ HIF-1 $\alpha$ siRNA (5'-CTACTC AGGACACAGATTTAGACTTGGAG-3) or negative control siRNA (5'-CAGCAACCAGGTGACCGTG-3') obtained from Guangzhou Ribobio Co. Ltd., Guangzhou, China, using the transfection reagent Lipofectamine 2000 (Invitrogen; Thermo Fisher Scientific Inc.) according to the manufacturer's protocol, $24 \mathrm{~h}$ prior to treatment with drugs.

CCK8 assay. CCK8 assays were performed in 96-well plates (100 $\mu \mathrm{l}$ cells, $5 \times 10^{6} / \mathrm{ml}$ suspension/well) according to the manufacturer's protocol. The cells were incubated with $10 \mu \mathrm{l} \mathrm{CCK}$ solution following the indicated treatment by exposing them to hypoxia in a chamber filled with a gas mixture of $1 \% \mathrm{O}_{2} / 5 \%$ $\mathrm{CO}_{2} / 94 \% \mathrm{~N}_{2}$. Absorbance was measured at a wavelength of $450 \mathrm{~nm}$ using a microplate reader (Bio-Rad laboratories Inc., Hercules, CA, USA) at 1-4 h. Cell viability was expressed as a percentage of the value of the control cultures, following subtraction of the background absorbance.

Evaluation of cell death by flow cytometry. Cells were pretreated with $3 \mu \mathrm{M} 2 \mathrm{ME} 2$ for $6 \mathrm{~h}$ or transfected with $50 \mathrm{nM}$ HIF-1 $\alpha$ siRNA prior to hypoxia exposure for 3, 6, 9, 12 and 24 h. Following exposure to hypoxia and drugs, cells were washed twice with phosphate buffered saline (PBS), adjusted to a concentration of $1 \times 10^{6}$ cells $/ \mathrm{ml}$, fixed with $70 \%$ ethanol on ice for $30 \mathrm{~min}$, resuspended in $1 \mathrm{ml}$ binding buffer (Seebio Shanghai, China) and incubated at $4^{\circ} \mathrm{C}$ for $15 \mathrm{~min}$ in the dark with $20 \mu \mathrm{g} / \mathrm{ml}$ annexin V-FITC and $50 \mu \mathrm{g} / \mathrm{ml}$ propidium iodide. Samples were analyzed using Cytomics ${ }^{\mathrm{TM}}$ FC500 Summit Software, Version 4.3 (Beckman Coulter, Inc., Brea, CA, USA) by flow cytometry using a BD FACSCanto II cytometer (BD Biosciences, Franklin Lakes NJ, USA).

Transmission electron microscopy (TEM). Thin sections were cut with a diamond knife on an Ultra $45^{\circ} \mathrm{C}$ (Daitome AG, Nidau, Switzerland) and examined using a Tecnai G2 20 Twin transmission electron microscope (FEI, Hillsboro, OR, USA). Uranium lead double staining (with $2 \%$ uranyl acetate saturated aqueous solution, and then citrate for $15 \mathrm{~min}$ each). Ultrastructural features of autophagy in microglial cells were studied by TEM as previously described (25). Briefly, microglial cells were harvested following exposure to hypoxia, washed with PBS, fixed with $1 \%$ glutaraldehyde in $0.1 \mathrm{M}$ cacodylate buffer for $2 \mathrm{~h}$ at $4^{\circ} \mathrm{C}$, then post-fixed with $1 \% \mathrm{OsO}_{4}$ for $1.5 \mathrm{~h}$ in the same buffer at $20^{\circ} \mathrm{C}$. The samples were then washed, dehydrated, and embedded in 812 embedding medium (SPI Supplies, Inc, West Chester, PA, USA) at $20^{\circ} \mathrm{C}$ for $12 \mathrm{~h}$. Thin sections (60-80 $\mathrm{nm})$ were cut with a diamond knife on an Ultra $45^{\circ} \mathrm{C}$ (Daitome AG) and examined using a Tecnai G2 20 Twin transmission electron microscope (FEI, Hillsboro, OR, USA).

IHC staining. BV2 cells were plated on cover slips in 24-well plates and exposed to hypoxia or treated with drugs. IHC staining of LC3-II was performed to determine expression level alterations of LC3-II following exposure to hypoxia. Briefly, the cells were fixed with $4 \%$ paraformaldehyde, permeabilized with $0.3 \%$ Triton X-100, blocked with 5\% goat serum for $40 \mathrm{~min}$, and incubated with rabbit anti-LC3-II antibodies (1:100; cat. no. ab51520) diluted in PBS overnight at $4^{\circ} \mathrm{C}$. Subsequently, cells were stained with the tetramethylrhodamine-conjugated anti-rabbit IgG secondary antibody (1:100; cat. no. 111-095-003) for $2 \mathrm{~h}$ at room temperature. The cells were counterstained with DAPI for 5 min following rinsing with PBS. The images were captured on a fluorescence microscope (Olympus Corporation, Tokyo, Japan).

$R T$ - $q P C R$. RT-qPCR was performed to measure mRNA expression levels of HIF-1 $\alpha$, in BV2 cells. Total RNA was extracted using TRIzol reagent (Thermo Fisher Scientific, Inc.), and the reverse-transcription reactions were performed using a TaqMan MicroRNA Reverse Transcription kit (Takara Bio, Inc., Otsu, Japan). qPCR was performed using a standard SYBR Green PCR kit (Takara Bio, Inc.) in a 7900 Real-time PCR system (Applied Biosystems, Thermo Fisher Scientific Inc.) according to the manufacturer's protocol. The thermocycling conditions used for the PCR were as follows: $95^{\circ} \mathrm{C}$ for $30 \mathrm{sec}$, followed by 40 cycles of $95^{\circ} \mathrm{C}$ for $3 \mathrm{sec}$ and $60^{\circ} \mathrm{C}$ for $30 \mathrm{sec}$. The sequences of primers used were as follows: HIF-1 $\alpha$, forward 5'-TGCTTGGTGCTGATTTGTGA-3' and reverse 5'-GGTCAGATGATCAGAGTCCA-3'; and $\beta$-actin, forward 5'-TTCCTTCCTGGGCATGGAGTCC-3' and reverse 5'-TGGCGTACAGGTCTTTGCGG-3'. $\beta$-actin was used as a reference for mRNAs and each sample was analyzed in triplicate. Relative levels of gene expression were quantified using the $2^{-\Delta \Delta \mathrm{Cq}}$ method (26).

Western blotting. Protein expression of Beclin-1 and LC3-II in treated and untreated BV2 cells was analyzed by western blotting. Briefly, BV2 cells were harvested at the indicated time, washed three times with ice-cold PBS, and RIPA buffer was used to extract total and nuclear proteins. The BCA protein assay was then used to determine protein concentration. Following this, equal amounts of protein $(20 \mu 1500 \mathrm{ng} / \mathrm{ml})$ were separated on $10 \%$ SDS-PAGE minigels and transferred to nitrocellulose membranes. The membranes were then blocked using 5\% skimmed milk for $60 \mathrm{~min}$, and incubated with rabbit primary antibodies against HIF-1 $\alpha$, Beclin-1 and LC3-II at a 1:200 dilution overnight at $4^{\circ} \mathrm{C}$. Subsequently, the membranes were washed three times for $10 \mathrm{~min}$ each with Tris-buffered saline with Tween-20 (0.05\%; TBST) and incubated with the corresponding secondary antibodies for $2 \mathrm{~h}$ at room temperature. Blots were washed three times for $10 \mathrm{~min}$ each in TBST and scanned with the Bio-Rad western blot system (Bio-Rad Laboratories, Inc.). Blots were washed three times for 10 min each in TBST. Immunoblots were detected using an enhanced chemiluminescence kit (cat. no. NC32109; Thermo Fisher Scientific, Inc.). Autoradiographs were quantitated by the Bio-Rad western blot system (Bio-Rad Laboratories, Inc.). Background intensity was subtracted from each sample and normalized to the $\beta$-actin loading control. Protein expression was quantified using an Image Lab 4.0 software system (Bio-Rad Laboratories, Inc.). Background intensity was subtracted from each sample and normalized to the $\beta$-actin loading control. 
ELISA. Supernatants were collected from cell cultures at different time points following exposure to various stimuli. Cells were stimulated with transfection of $50 \mathrm{nM}$ HIF-1 $\alpha$ siRNA or pretreatment with $3 \mu \mathrm{M} 2 \mathrm{ME} 2$ for $6 \mathrm{~h}$ prior to hypoxia exposure. Secretion of cytokines TNF- $\alpha$ and IL-1 $\beta$ in the supernatants was measured using ELISA kits (TNF- $\alpha$, cat. no. 88-7340-22; IL-1 $\beta$, cat. no. 88-7010-77) according to the manufacturer's protocols (eBioscience, Inc., San Diego, CA, USA). Absorbance was measured at a wavelength of $405 \mathrm{~nm}$ on a Bio-Rad iMark microplate reader (Bio-Rad Laboratories, Inc.). The protein concentrations $(\mathrm{pg} / \mathrm{ml})$ were calculated from a standard curve.

Statistical analysis. Statistical analyses were conducted using SPSS software, version 18.0 (SPSS, Inc., Chicago, IL, USA). All data are expressed as the mean \pm standard error of the mean. Differences between groups were compared by one-way analysis of variance followed by Bonferroni post-hoc multiple comparison test. Each experiment included at least 3 replicates per condition. $\mathrm{P}<0.05$ was considered to indicate a statistically significant difference.

\section{Results}

Hypoxia-induces cell death and inflammation in microglial cells. To elucidate the role of hypoxia in microglial cell death, the primary microglial cells and BV2 cells were exposed to hypoxia for 3, 6, 9, 12 and $24 \mathrm{~h}$. Cell viability was measured by CCK- 8 assay, which is considered an effective method for the detection of cell death. As presented in Fig. 1A, statistically significant time-dependent decreases in relative cell viability were observed under hypoxic conditions in both cell types ( $\mathrm{P}<0.001$ vs. $0 \mathrm{~h}$ ). Similar results were obtained by flow cytometry: Hypoxia induced apoptosis in microglial cells $(\mathrm{P}<0.001$ vs. $0 \mathrm{~h}$ Fig. $1 \mathrm{~B})$. It has previously been demonstrated that hypoxia rapidly induces cell death through inflammation (27). To examine the effects of hypoxia on neuroinflammation in microglial cells, the expression of inflammatory cytokines IL-1 $\beta$ and TNF- $\alpha$ in hypoxia-exposed microglial cells was investigated by ELISA. As presented in Fig. 1C, hypoxia significantly increased the protein levels of IL- $1 \beta$ and TNF- $\alpha$, reaching a peak at $6 \mathrm{~h}$ exposure compared with $0 \mathrm{~h}$ exposure $(\mathrm{P}<0.001)$. Overall, the results demonstrated that hypoxia induced cell death and inflammation in microglial cells.

Hypoxia-induces expression of HIF-1 $\alpha$ in BV2 cells. HIF-1 $\alpha$ is expressed at a significantly high level under hypoxic conditions and heterodimerizes with HIF-1 $\beta$ to form HIF-1, following translocation into the nucleus (28). The present study investigated whether hypoxia-induced cell death was HIF-1 $\alpha$-dependent. It was observed that hypoxia significantly increased HIF-1 $\alpha$ mRNA expression levels at 3, 6, 9, 12 and 24 h compared with $0 \mathrm{~h}(\mathrm{P}<0.05, \mathrm{P}<0.001, \mathrm{P}<0.001, \mathrm{P}<0.001$ and $\mathrm{P}<0.001$, respectively; Fig. 2A). The greatest level of expression of HIF-1 $\alpha$ mRNA was observed at $6 \mathrm{~h}$ compared with $0 \mathrm{~h}(\mathrm{P}<0.001$; Fig. 2A) and comparable results were observed by western blotting, with hypoxia significantly increasing HIF-1 $\alpha$ protein expression levels at 3, 6, 9, 12 and 24 h compared with 0 h $(\mathrm{P}<0.001, \mathrm{P}<0.001, \mathrm{P}<0.001, \mathrm{P}<0.001$ and $\mathrm{P}<0.05$, respectively; Fig. $2 \mathrm{~B}$ ). These data indicated that hypoxia induced the expression of HIF-1 $\alpha$ in microglial cells. This effect was observed in groups exposed to hypoxia for $6 \mathrm{~h}$, which suggested that HIF-1 $\alpha$ is important in hypoxia-induced cell death.

HIF-1a mediates microglial cell autophagy induced by hypoxia in BV2 cells. It has previously been suggested that SCI-associated hypoxia may induce autophagy in microglial cells (29,30). Beclin-1 and LC-3 are characteristic marker proteins of autophagy. The expression levels of LC3-II and Beclin-1 were investigated to determine whether autophagy is induced as a result of the expression of HIF-1 $\alpha$ following exposure to hypoxia. As presented in Fig. 3A, the protein expression levels of LC3-II and Beclin-1 reached their peak in hypoxic cells after $3 \mathrm{~h}$ hypoxia compared with $0 \mathrm{~h}(\mathrm{P}<0.001)$. Ultrastructural alterations in hypoxia-treated microglial cells were examined and compared with controls without hypoxia treatment (Fig. 3B). Closed arrows indicate the presence of autophagosomes in hypoxia-treated microglial cells (Fig. 3B). This indicates high expression of autophagosomes in hypoxia-treated microglial cells. As presented in Fig. 3C, the protein accumulation of LC3-II visualized by immunofluorescence was visibly increased in hypoxic cells compared with $0 \mathrm{~h}$ hypoxia control.

HIF-1 $\alpha$ mediates hypoxia-induced cell death and inflammation via autophagy in BV2 cells. The previous results illustrate that hypoxia induces a complete autophagic response in microglial cells, and HIF-1 $\alpha$ may mediate microglial cell autophagy under conditions of hypoxia. Microglial cells were exposed to the HIF-1 $\alpha$ inhibitor $2 \mathrm{ME} 2$ or silenced with HIF-1 $\alpha$ siRNA (100 nM each) for $6 \mathrm{~h}$, to investigate whether hypoxia-induced autophagy promoted microglial cell survival or death, and to explore the associated mechanism of action. The mRNA and protein expression levels of the HIF-1 $\alpha$ target were evaluated by RT-qPCR and western blotting assays respectively. Cell death and inflammation induced by hypoxic conditions in cells with inhibited HIF-1 $\alpha$ were additionally evaluated.

At each time point, HIF-1 $\alpha$ inhibition and HIF-1 $\alpha$ silencing significantly decreased hypoxia-induced HIF-1 $\alpha$ mRNA expression compared with the uninhibited control at the same time point (2ME2 3 and $12 \mathrm{~h}, \mathrm{P}<0.05$ and $\mathrm{P}<0.05$, respectively; HIF- $1 \alpha$ siRNA 3 and $12 \mathrm{~h}, \mathrm{P}<0.05$ and $\mathrm{P}<0.05$, respectively; Fig. 4A). In addition, at each time point, HIF-1 $\alpha$ inhibition and HIF-1 $\alpha$ silencing visibly decreased hypoxia-induced HIF-1 $\alpha$ protein expression compared with the uninhibited control at the same time point (Fig. 4B). LC3-II protein expression levels were significantly reduced at 3 and $12 \mathrm{~h}$ in BV2 cells following transfection with siRNAs targeting HIF-1 $\alpha$, compared with controls at the same time points $(\mathrm{P}<0.05$ and $\mathrm{P}<0.05$, respectively, Fig. 4C) and Beclin-1 protein expression levels were significantly reduced at $3 \mathrm{~h}$ compared with controls at $3 \mathrm{~h}$ $(\mathrm{P}<0.05$; Fig. 4C).

Additional studies revealed that chemical inhibition of HIF-1 $\alpha$ or HIF-1 $\alpha$ siRNA knockdown decreased hypoxia-induced cell viability at 3 and $12 \mathrm{~h}$ compared with controls at the same time points (2ME2 3 and $12 \mathrm{~h}, \mathrm{P}<0.05$ and $\mathrm{P}<0.05$, respectively; HIF- $1 \alpha$ siRNA 3 and $12 \mathrm{~h}, \mathrm{P}<0.05$ and $\mathrm{P}<0.05$, respectively; Fig. 4D). This effect was observed 
A

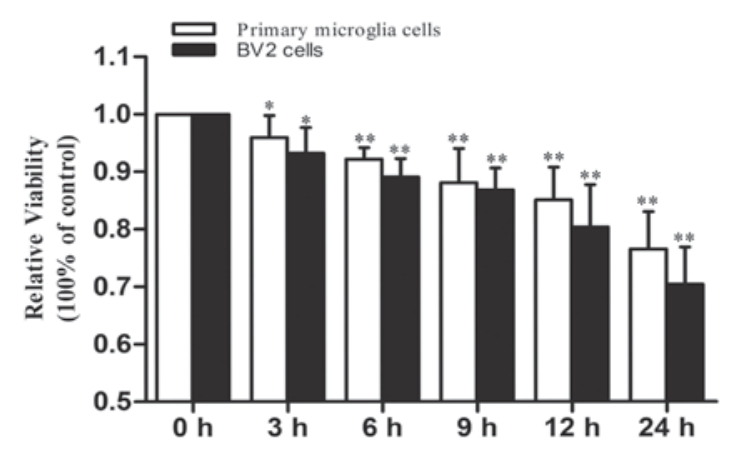

B

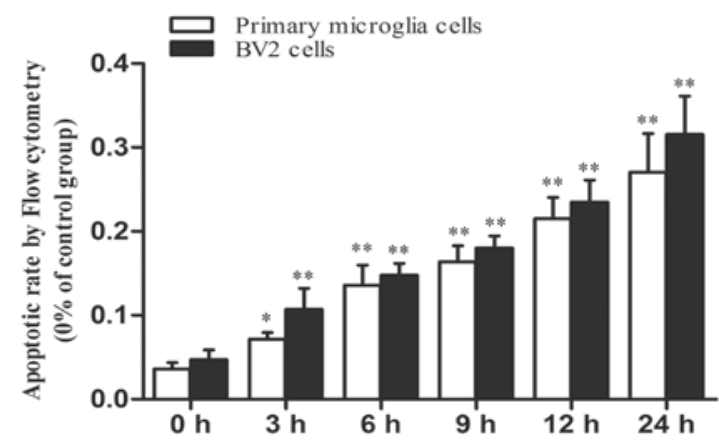

$\mathrm{C}$

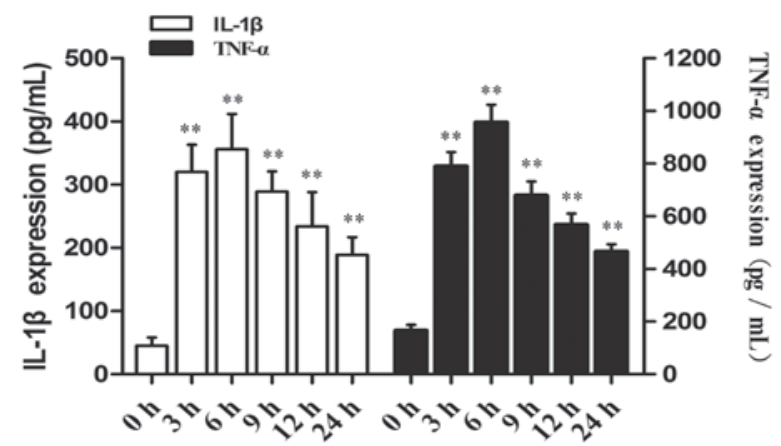

Figure 1. Hypoxia induces cell death and inflammation in microglia cells. (A) The effect of hypoxia on cell viability was assessed by Cell Counting Kit-8 assay. Microglia were exposed to hypoxic conditions for the indicated time periods. (B) In vitro microglia cell death was assessed by Annexin V-FITC/propidium iodide staining and flow cytometry. (C) Protein expression levels of IL-1 $\beta$ and TNF- $\alpha$ were determined by ELISA. Data are presented as the mean \pm standard deviation of three independent experiments. ${ }^{*} \mathrm{P}<0.05$ and ${ }^{* *} \mathrm{P}<0.001$ vs. 0 h. IL- $1 \beta$, interleukin- $\beta$; TNF- $\alpha$, tumor necrosis factor- $\alpha$.

to be associated with alterations in the expression of inflammatory cytokines in BV2 cells: the production of IL-1 $\beta$ was significantly increased in BV2 cells treated with the inhibitor 2ME2 and transfected with siRNAs targeting HIF-1 $\alpha$ at 3 and $12 \mathrm{~h}$ compared with controls without pre-treatment at the same time points $(2 \mathrm{ME} 23$ and $12 \mathrm{~h}, \mathrm{P}<0.05$ and $\mathrm{P}<0.05$, respectively; HIF-1 $\alpha$ siRNA 3 and $12 \mathrm{~h}, \mathrm{P}<0.05$ and $\mathrm{P}<0.05$, respectively; Fig. 4E) and $\mathrm{TNF}-\alpha$ expression was also significantly increased in BV2 cells treated with the inhibitor 2ME2 and transfected with siRNAs targeting HIF-1 $\alpha$ at 3 and $12 \mathrm{~h}$ compared with controls without pre-treatment at
A

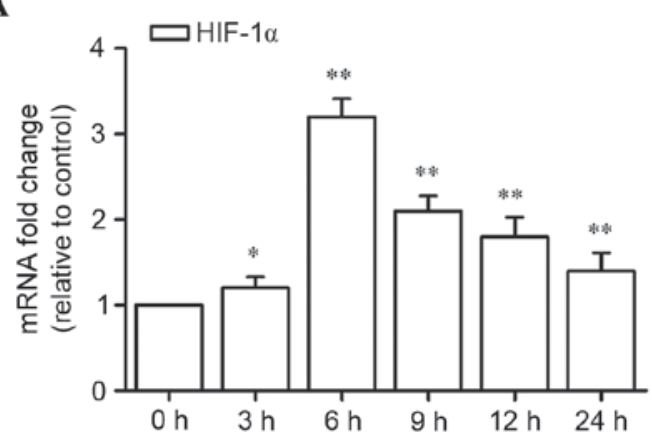

B
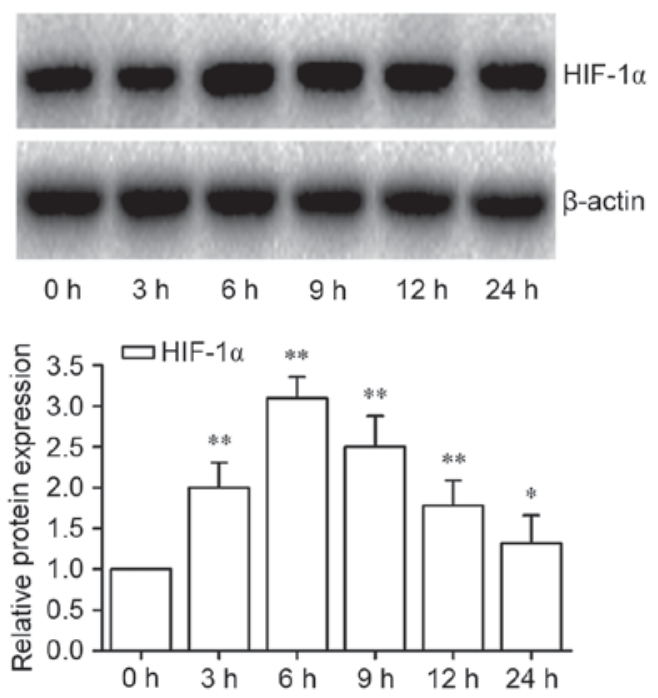

Figure 2. HIF-1 $\alpha$ mediates hypoxia-induced cell death. (A) Reverse transcription-quantitative polymerase chain reaction was used to determine mRNA expression levels of HIF-1 $\alpha$ in microglia cells following exposure to hypoxic conditions for $0,3,6,9,12$ and $24 \mathrm{~h}$. (B) HIF-1 $\alpha$ protein expression levels in microglia were detected by western blot assay following exposure to hypoxic conditions for $0,3,6,9,12$ and $24 \mathrm{~h}$, and quantified relative to $\beta$-actin. Data are presented as the mean \pm standard deviation of three independent experiments. ${ }^{*} \mathrm{P}<0.05$ and ${ }^{* *} \mathrm{P}<0.001$ vs. 0 h. HIF-1 $\alpha$, hypoxia-inducible factor $1-\alpha$.

the same time points (2ME2 3 and $12 \mathrm{~h}, \mathrm{P}<0.05$ and $\mathrm{P}<0.05$, respectively; HIF-1 $\alpha$ siRNA 3 and 12 h, $\mathrm{P}<0.05$ and $\mathrm{P}<0.05$, respectively; Fig. 4F).

These data suggested that inhibition of HIF-1 $\alpha$ decreased cell death via controlled overexpression of inflammatory cytokines in BV2 cells. HIF-1 $\alpha$ may therefore mediate the autophagic death of microglial cells via regulation of autophagy-associated gene expression and cytokine release.

\section{Discussion}

In the present study, the effects and mechanism of action of hypoxia-induced autophagic cell death in microglial cells were investigated. The results demonstrated that hypoxia induced cell death and inflammation in microglial cells. HIF-1 $\alpha$ mediated hypoxia tolerance in hypoxia-induced autophagic cell death in microglial cells. The present study suggested that effects may be associated with modulating the expression of autophagy-associated genes and the inflammatory response following hypoxia in microglial cells. 
A

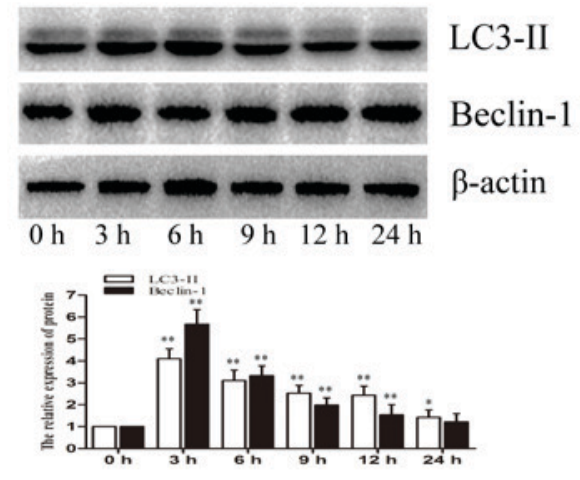

B

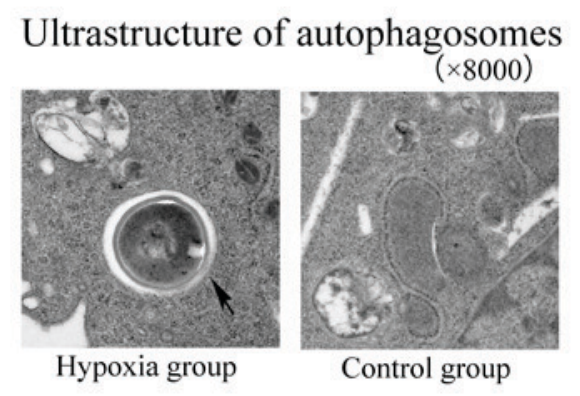

$\mathrm{C}$

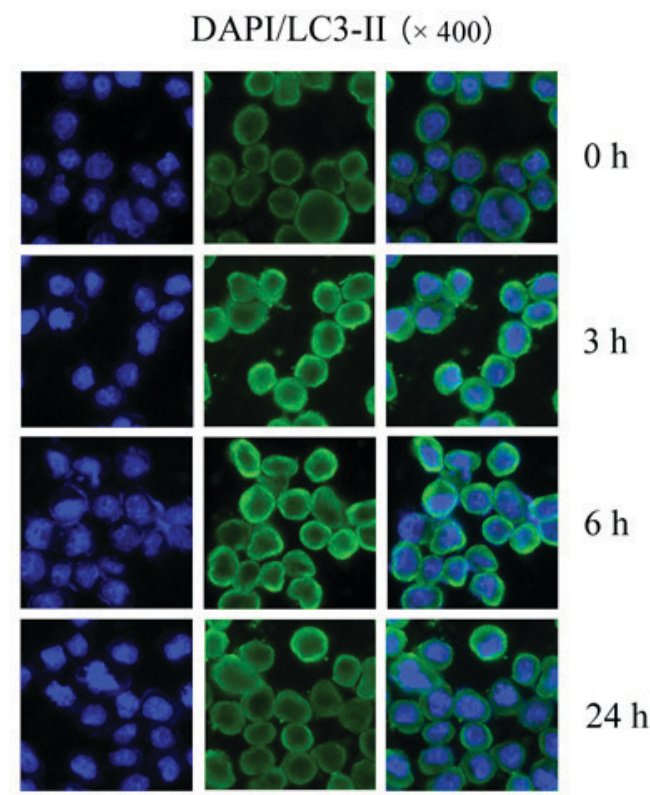

Figure 3. HIF-1 $\alpha$ mediates microglia autophagy induced by hypoxia in BV2 cells. (A) LC3-II and Beclin-1 protein expression levels were evaluated by western blotting following exposure to hypoxic conditions for $0,3,6,9,12$ and $24 \mathrm{~h}$, and quantified relative to $\beta$-actin. (B) Ultrastructural changes in hypoxia-treated microglia. Samples without hypoxia treatment served as controls. Closed arrows indicate autophagosomes. (C) Immunofluorescence of LC3-II in BV2 cells following exposure to hypoxic conditions for 0, 3, 6 and $12 \mathrm{~h}$. Data are presented as the mean \pm standard deviation of three independent experiments. ${ }^{*} \mathrm{P}<0.05$ and ${ }^{* *} \mathrm{P}<0.001$ vs. 0 h. HIF- $1 \alpha$, hypoxia-inducible factor 1- $\alpha$; LC3-II, microtubule-associated protein 1A/1B-light chain 3 phosphatidylethanolamine conjugate.

SCI, which is characterized by primary physical and secondary damage, leads to severe consequences including paralysis, intense pain and progressive neurological damage (31). Primary spinal cord injuries attributed to mechanical forces are characterized by acute hemorrhage and ischemia, whereas secondary injuries are associated with an inflammatory response, further characterized by further destruction of neuronal and glial cells, resulting in the release of reactive oxygen species and pro-inflammatory cytokines $(32,33)$. Macrophages in the CNS derived from blood monocytes or resident microglial cells, and microglial cells, are important in maintaining and restoring CNS homeostasis. Macrophages accumulate within the epicenter of the injury and the hematoma of the injured spinal cord under pathological conditions, and may be important in the progression of inflammation (34). Pro-inflammatory cytokines including TNF- $\alpha$, IL- $1 \beta$, and IL- 6 and inflammatory mediators, including inducible nitric oxide synthase and cyclooxygenase- 2 are rapidly upregulated following SCI $(35,36)$. However, the mechanisms by which microglial cells control pro-inflammatory cytokines during SCI have not been fully elucidated.

To investigate the effect of hypoxia on cell viability and pro-inflammatory cytokines in microglial cells, the present study first performed a cell death assay and detected the secretion of pro-inflammatory cytokines. These data indicated that hypoxia gradually induced cell death along with an increase in inflammation, and this was consistent with data from previous reports $(37,38)$.

HIF-1 is a heterodimeric transcription factor that contains the protein HIF-1 $\alpha$ and an arylhydrocarbon receptor nuclear translocator (HIF-1 $\beta$ ) (39). The availability of HIF-1 is primarily determined by levels of HIF-1 $\alpha$, which is stably expressed. The expression and activity of the HIF-1 $\alpha$ subunit are regulated by the cellular oxygen concentration. HIF-1 $\alpha$ is expressed at a high level under hypoxic conditions, and heterodimerizes with HIF-1 $\beta$ to form HIF-1 following translocation to the nucleus. At an early stage of hypoxia, induction of HIF-1 may protect cells from destruction $(40,41)$.

The present study investigated whether HIF-1 $\alpha$ was involved in cell death induced by hypoxia. The expression of HIF-1 $\alpha$ increased in a time-dependent manner under hypoxic conditions. During cerebral anoxemia, the activation of HIF-1 $\alpha$ is an important activator of microglial cells (42). In addition, microglial cells were exposed to a HIF-1 $\alpha$ inhibitor and HIF-1 $\alpha$ siRNA to evaluate the association between hypoxic conditions and subsequent cell death.

Autophagy is a cardinal cellular mechanism that involves degradation and digestion of intracellular constituents by lysosomes $(43,44)$. Autophagy is important under physiological conditions for numerous immune cells including macrophages $(16,45)$. It has previously been suggested that autophagy has a cytoprotective function against cell death (46) and may contribute to cytoprotection in neurodegenerative disease and traumatic brain injury $(47,48)$. Conversely, abrogated autophagy may induce cell death $(49,50)$. Autophagy may lead to non-apoptotic programmed cell death, known as autophagic cell death. LC-3, a homolog of yeast autophagy-related protein $8(\operatorname{Atg} 8)$, is essential for autophagy: It is important in the formation of the autophagosome and is considered to be another specific marker protein to monitor autophagy (51). LC3-II is a widely used marker for autophagy; 
A

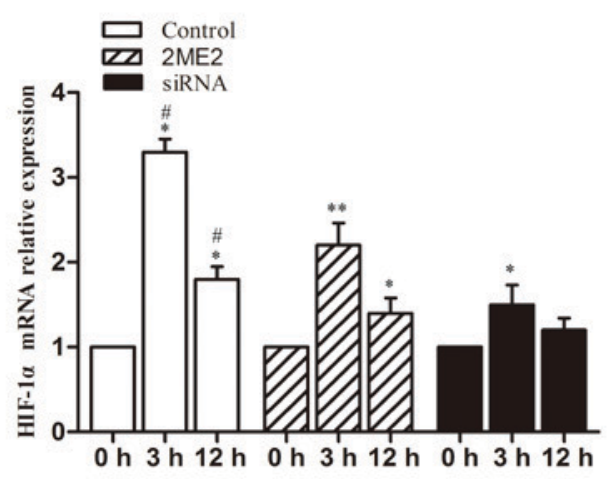

C

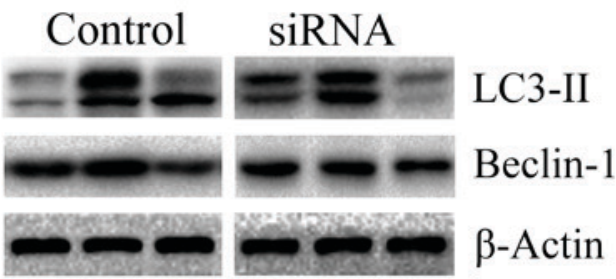

$0 \mathrm{~h} \quad 3 \mathrm{~h} 12 \mathrm{~h} \quad 0 \mathrm{~h} \quad 3 \mathrm{~h} 12 \mathrm{~h}$

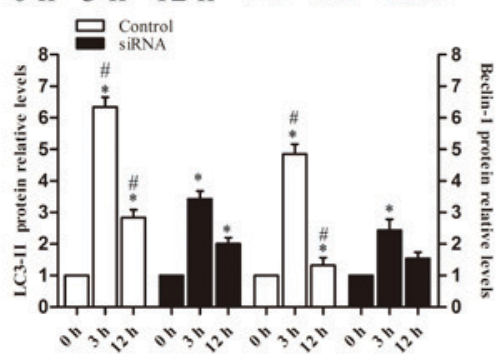

E

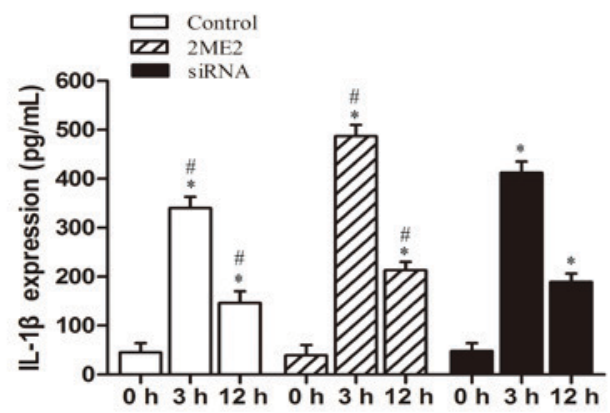

B

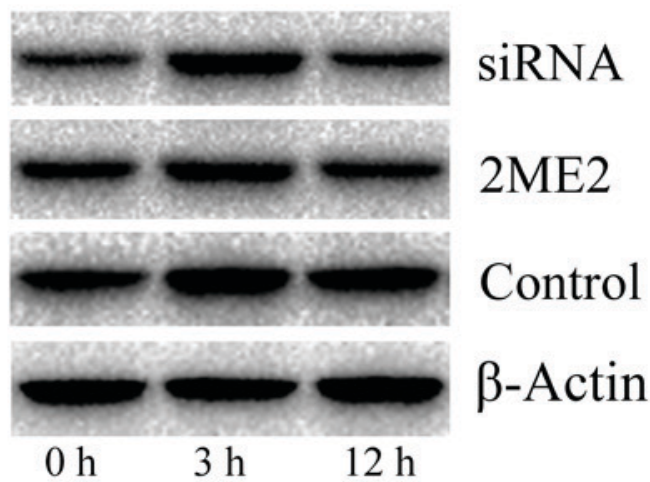

D

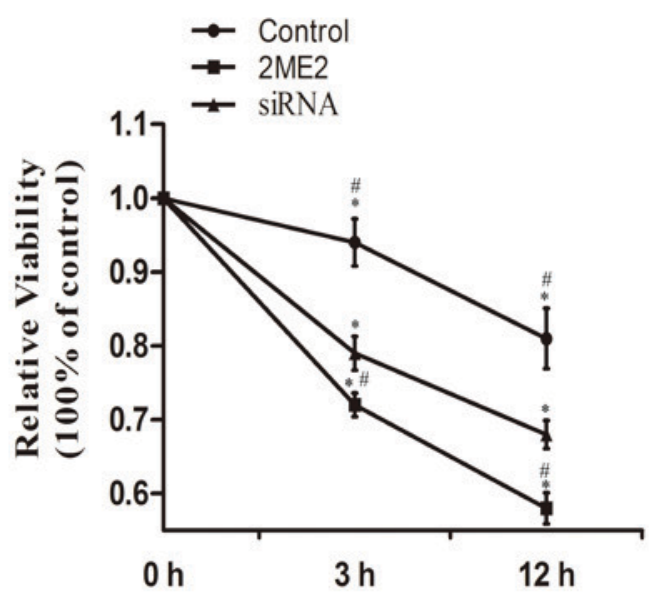

F

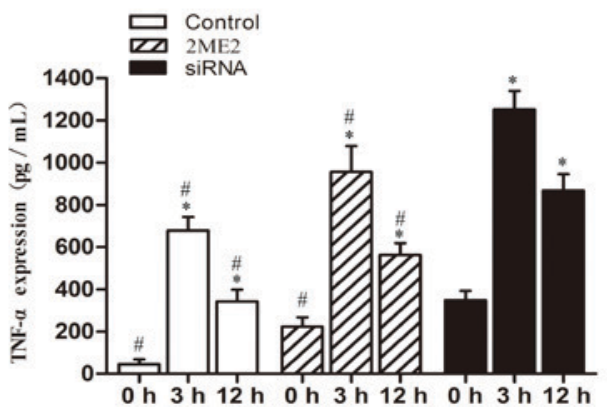

Figure 4. HIF-1 $\alpha$ mediates hypoxia-induced cell death and inflammation by autophagy in BV2 cells. Detection of efficiency of HIF-1 $\alpha$ inhibitors and siRNAs on HIF-1 $\alpha$ expression following hypoxia in BV2 cells. Microglia cells were pretreated with $3 \mu \mathrm{M} 2 \mathrm{ME} 2$ or with siRNA targeting HIF-1 $\alpha$ (100 nM) for $6 \mathrm{~h}$, and (A) mRNA and (B) protein expression levels of the target were evaluated by quantitative polymerase chain reaction and western blot assays, respectively. (C) Detection of the effect of HIF-1 $\alpha$ inhibition on LC3-II and Beclin-1 protein expression in BV2 cells following hypoxia. Protein expression levels were evaluated by western blot and quantified relative to $\beta$-actin. (D) Viability of microglia cells exposed to the inhibitors following 0,3 and $12 \mathrm{~h}$ hypoxia was assessed by Cell Counting Kit-8 assay. Protein expression levels of (E) IL-1 $\beta$ and (F) TNF- $\alpha$ were determined by ELISA in microglia cells exposed to the inhibitors and 0, 3 and $12 \mathrm{~h}$ hypoxia. Data are expressed as the mean \pm standard deviation of three independent experiments. ${ }^{*} \mathrm{P}<0.05,{ }^{* *} \mathrm{P}<0.001 \mathrm{vs}$. the $0 \mathrm{~h}$ control time point); ${ }^{~} \mathrm{P}<0.05,{ }^{\# \#} \mathrm{P}<0.001$ vs. the equivalent time point siRNA) HIF-1 $\alpha$, hypoxia-inducible factor 1- $\alpha$; LC3-II, microtubule-associated protein 1A/1B-light chain 3 phosphatidylethanolamine conjugate; IL-1 $\beta$, interleukin- $\beta$; TNF- $\alpha$, tumor necrosis factor- $\alpha$; siRNA, small interfering RNA; $2 \mathrm{ME2}$, 2-methoxyestradiol. 
during autophagy, the cytosolic LC3-I form is converted to an autophagosome-bound LC3-II form $(52,53)$. Beclin-1 is another autophagy-associated protein, which is important in regulating the development of precursors of autophagosomes from other autophagy-associated proteins (54). Beclin-1 and LC-3 are, therefore, characteristic markers of autophagy (55).

Therefore, to further determine whether autophagy is induced under hypoxic conditions, the expression of LC3-II and Beclin-1 was investigated. Hypoxia induced a complete autophagic response in microglial cells. In addition, autophagy was observed by inhibiting HIF- $\alpha$ activation in microglial cells via a HIF-1 $\alpha$ inhibitor or HIF-1 $\alpha$ siRNA. It was observed that HIF-1 $\alpha$ mediated microglial cell autophagy under hypoxic conditions.

Neuroinflammation is characterized by the activation of microglial cells, and contributes to the development of numerous neurological conditions, including CNS infections, ischemic stroke, neurodegenerative diseases and anesthetic neurotoxicity, through the production of various pro-inflammatory mediators, which promote neuronal cell death $(38,56)$. Autophagy controls inflammation through interactions with immune signaling pathways and regulates secretion of inflammatory molecular mediators $(19,57)$. However, the pathways of microglial cells controlling pro-inflammatory cytokines under hypoxic conditions during SCI have not yet been elucidated. The present study examined the extent of cell death and inflammation induced by hypoxia. The results demonstrated that HIF-1 $\alpha$ was important in hypoxia-induced cell death and mediated microglial cell autophagic cell death via regulation of autophagy-associated genes and cytokine release.

In conclusion, the present study demonstrated that hypoxia enhanced the expression of HIF-1 $\alpha$ in microglial cells and resulted in autophagic cell death through the activation of microglial cells. Expression of HIF-1 $\alpha$ inhibited the overexpression of the inflammatory cytokine in microglial cells at an early stage of hypoxia. In addition, various autophagic factors including LC3-II and Beclin-1 were regulated by HIF-1 $\alpha$ in microglial cells, which mediated the expression of a variety of inflammatory cytokines. HIF-1 $\alpha$ stimulated the production inflammatory cytokines via autophagic factors in microglial cells under hypoxic conditions, thus enhancing the tolerance of microglial cells to hypoxia during hypoxic conditions, which may represent a potential therapeutic approach against diseases, including ischemic/hypoxic SCI.

\section{References}

1. Amar AP and Levy ML: Pathogenesis and pharmacological strategies for mitigating secondary damage in acute spinal cord injury. Neurosurgery 44: 1027-1040, 1999.

2. Fleming JC, Norenberg MD, Ramsay DA, Dekaban GA, Marcillo AE, Saenz AD, Pasquale-Styles M, Dietrich WD and Weaver LC: The cellular inflammatory response in human spinal cords after injury. Brain 129: 3249-3269, 2006.

3. Dolan EJ and Tator CH: The effect of blood transfusion, dopamine, and gamma hydroxybutyrate on posttraumatic ischemia of the spinal cord. J Neurosurg 56: 350-358, 1982.

4. Webb AA, Ngan S and Fowler JD: Spinal cord injury I: A synopsis of the basic science. Can Vet J 51: 485-492, 2010.

5. Brown GC and Neher JJ: Inflammatory neurodegeneration and mechanisms of microglial killing of neurons. Mol Neurobiol 41: 242-247, 2010.
6. Magazine HI, Liu Y, Bilfinger TV, Fricchione GL and Stefano GB: Morphine-induced conformational changes in human monocytes, granulocytes, and endothelial cells and in invertebrate immunocytes and microglia are mediated by nitric oxide. J Immunol 156: 4845-4850, 1996.

7. Perry VH, Nicoll JA and Holmes C: Microglia in neurodegenerative disease. Nat Rev Neurol 6: 193-201, 2010.

8. Carlson SL, Parrish ME, Springer JE, Doty K and Dossett L: Acute inflammatory response in spinal cord following impact injury. Exp Neurol 151: 77-88, 1998.

9. Donnelly DJ and Popovich PG: Inflammation and its role in neuroprotection, axonal regeneration and functional recovery after spinal cord injury. Exp Neurol 209: 378-388, 2008.

10. de Lemos ML, de la Torre AV, Petrov D, Brox S, Folch J, Pallàs M, Lazarowski A, Beas-Zarate C, Auladell C and Camins A: Evaluation of hypoxia inducible factor expression in inflammatory and neurodegenerative brain models. Int J Biochem Cell Biol 45: 1377-1388, 2013.

11. Semenza GL: Expression of hypoxia-inducible factor 1: Mechanisms and consequences. Biochem Pharmacol 59: 47-53, 2000.

12. Yeo EJ, Chun YS and Park JW: New anticancer strategies targeting HIF-1. Biochem Pharmacol 68: 1061-1069, 2004.

13. Bergeron M, Gidday JM, Yu AY, Semenza GL, Ferriero DM and Sharp FR: Role of hypoxia-inducible factor-1 in hypoxia-induced ischemic tolerance in neonatal rat brain. Ann Neurol 48: 285-296, 2000.

14. Sheldon RA, Osredkar D, Lee CL, Jiang X, Mu D and Ferriero DM: HIF-1 alpha-deficient mice have increased brain injury after neonatal hypoxia-ischemia. Dev Neurosci 31: 452-458, 2009.

15. Yang $\mathrm{Z}$ and Klionsky DJ: Mammalian autophagy: Core molecular machinery and signaling regulation. Curr Opin Cell Biol 22: 124-131, 2010.

16. Singh SB, Davis AS, Taylor GA and Deretic V: Human IRGM induces autophagy to eliminate intracellular mycobacteria. Science 313: 1438-1441, 2006.

17. Lee J, Kim HR, Quinley C, Kim J, Gonzalez-Navajas J, Xavier R and Raz E: Autophagy suppresses interleukin-1 $\beta$ (IL-1 $\beta$ ) signaling by activation of $\mathrm{p} 62$ degradation via lysosomal and proteasomal pathways. J Biol Chem 287: 4033-4040, 2012.

18. Oka T, Hikoso S, Yamaguchi O, Taneike M, Takeda T, Tamai T, Oyabu J, Murakawa T, Nakayama H, Nishida K, et al: Mitochondrial DNA that escapes from autophagy causes inflammation and heart failure. Nature 485: 251-255, 2012.

19. Korkaya $\mathrm{H}$ and Wicha MS: Inflammation and autophagy conspire to promote tumor growth. Cell Cycle 10: 2623-2624, 2011.

20. Puyal J and Clarke PG: Targeting autophagy to prevent neonatal stroke damage. Autophagy 5: 1060-1061, 2009.

21. Rosello A, Warnes G and Meier UC: Cell death pathways and autophagy in the central nervous system and its involvement in neurodegeneration, immunity and central nervous system infection: To die or not to die-that is the question. Clin Exp Immunol 168: 52-57, 2012.

22. Willemen HL, Eijkelkamp N, Wang H, Dantzer R, Dorn GW II, Kelley KW, Heijnen CJ and Kavelaars A: Microglial/macrophage GRK2 determines duration of peripheral IL-1beta-induced hyperalgesia: Contribution of spinal cord CX3CR1, p38 and IL-1 signaling. Pain 150: 550-560, 2010.

23. Bocchini V, Mazzolla R, Barluzzi R, Blasi E, Sick P and Kettenmann H: An immortalized cell line expresses properties of activated microglial cells. J Neurosci Res 31: 616-621, 1992.

24. Sheng W,Zong Y,Mohammad A, AjitD, Cui J,Han D, Hamilton JL, Simonyi A, Sun AY, Gu Z, et al: Pro-inflammatory cytokines and lipopolysaccharide induce changes in cell morphology, and upregulation of ERK1/2, iNOS and SPLA (2)-IIA expression in astrocytes and microglia. J Neuroinflammation 8: 121, 2011.

25. Rabinovich GA, Riera CM and Iribarren P: Granulocyte-macrophage colony-stimulating factor protects dendritic cells from liposome-encapsulated dichloromethylene diphosphonate-induced apoptosis through a Bcl-2-mediated pathway. Eur J Immunol 29: 563-570, 1999.

26. Livak KJ and Schmittgen TD: Analysis of gene expression data using real-time quantitative PCR and the 2(-Delta Delta $\mathrm{C}(\mathrm{T})$ ) Method. Methods 25: 402-408, 2001.

27. Ratcliffe PJ, O'Rourke JF, Maxwell PH and Pugh CW: Oxygen sensing, hypoxia-inducible factor- 1 and the regulation of mammalian gene expression. J Exp Biol 201: 1153-1162, 1998.

28. Michel G, Minet E, Ernest I, Durant F. Remacle J and Michiels C: Molecular modeling of the hypoxia-inducible factor 1 (HIF-1). Theoretical Chemistry Accounts 101: pp51-56, 1999. 
29. Walker CL, Walker MJ, Liu NK, Risberg EC, Gao X, Chen J and Xu XM: Systemic bisperoxovanadium activates Akt/mTOR, reduces autophagy, and enhances recovery following cervical spinal cord injury. PloS One 7: e30012, 2012.

30. Kanno H, Ozawa H, Sekiguchi A and Itoi E: The role of autophagy in spinal cord injury. Autophagy 5: 390-392, 2009.

31. Oyinbo CA: Secondary injury mechanisms in traumatic spinal cord injury: A nugget of this multiply cascade. Acta Neurobiol Exp (Wars) 71: 281-299, 2011.

32. Hayashi M, Ueyama T, Nemoto K, Tamaki T and Senba E: Sequential mRNA expression for immediate early genes, cytokines, and neurotrophins in spinal cord injury. J Neurotrauma 17: 203-218, 2000.

33. Beattie MS: Inflammation and apoptosis: linked therapeutic targets in spinal cord injury. Trends Mol Med 10: 580-583, 2004.

34. Zhang YK, Liu JT, Peng ZW, Fan H, Yao AH, Cheng P, Liu L, Ju G and Kuang F: Different TLR4 expression and microglia/macrophage activation induced by hemorrhage in the rat spinal cord after compressive injury. J Neuroinflammation 10: 112, 2013.

35. Wang CX, Nuttin B, Heremans H, Dom R and Gybels $\mathrm{J}$ : Production of tumor necrosis factor in spinal cord following traumatic injury in rats. J Neuroimmunol 69: 151-156, 1996.

36. Yune TY, Chang MJ, Kim SJ, Lee YB, Shin SW, Rhim H, Kim YC, Shin ML, Oh YJ, Han CT, et al: Increased production of tumor necrosis factor-alpha induces apoptosis after traumatic spinal cord injury in rats. J Neurotrauma 20: 207-219, 2003.

37. Zhang L, Zhang J, Yang L, Dong Y, Zhang Y and Xie Z: Isoflurane and sevoflurane increase interleukin- 6 levels through the nuclear factor-kappa B pathway in neuroglioma cells. Br J Anaesth 110 (Suppl 1): i82-i91, 2013.

38. Gonzalez H, Elgueta D, Montoya A and Pacheco R: Neuroimmune regulation of microglial activity involved in neuroinflammation and neurodegenerative diseases. J Neuroimmunol 274: 1-13, 2014.

39. Cao Y, Mao X, Sun C, Zheng P, Gao J, Wang X, Min D Sun H, Xie N and Cai J: Baicalin attenuates global cerebral ischemia/reperfusion injury in gerbils via anti-oxidative and anti-apoptotic pathways. Brain Res Bull 85: 396-402, 2011.

40. Graumann U, Reynolds R, Steck AJ and Schaeren-Wiemers N: Molecular changes in normal appearing white matter in multiple sclerosis are characteristic of neuroprotective mechanisms against hypoxic insult. Brain Pathol 13: 554-573, 2003.

41. Schmid T, Zhou J and Brune B: HIF-1 and p53: Communication of transcription factors under hypoxia. J Cell Mol Med 8 423-431, 2004

42. Kyotani Y, Ota H, Itaya-Hironaka A, Yamauchi A, Sakuramoto-Tsuchida S, Zhao J, Ozawa K, Nagayama K, Ito S, Takasawa S, et al: Intermittent hypoxia induces the proliferation of rat vascular smooth muscle cell with the increases in epidermal growth factor family and erbB2 receptor. Exp Cell Res 319: 3042-3050, 2013

43. Jiang T, Yu JT, Zhu XC, Wang HF, Tan MS, Cao L, Zhang QQ, Gao L, Shi JQ, Zhang YD and Tan L: Acute metformin preconditioning confers neuroprotection against focal cerebral ischaemia by pre-activation of AMPK-dependent autophagy. $\mathrm{Br}$ J Pharmacol 171: 3146-3157, 2014.
44. Urbanek T, Kuczmik W, Basta-Kaim A and Gabryel B: Rapamycin induces of protective autophagy in vascular endothelial cells exposed to oxygen-glucose deprivation. Brain Res 1553: $1-11,2014$.

45. Nakahira K, Haspel JA, Rathinam VA, Lee SJ, Dolinay T, Lam HC, Englert JA, Rabinovitch M, Cernadas M, Kim HP, et al: Autophagy proteins regulate innate immune responses by inhibiting the release of mitochondrial DNA mediated by the NALP3 inflammasome. Nat Immunol 12: 222-230, 2011.

46. Rubinsztein DC, DiFiglia M, Heintz N, Nixon RA, Qin ZH, Ravikumar B, Stefanis L and Tolkovsky A: Autophagy and its possible roles in nervous system diseases, damage and repair. Autophagy 1: 11-22, 2005

47. Erlich S, Alexandrovich A, Shohami E and Pinkas-Kramarski R: Rapamycin is a neuroprotective treatment for traumatic brain injury. Neurobiol Dis 26: 86-93, 2007.

48. Sarkar S, Ravikumar B, Floto RA and Rubinsztein DC: Rapamycin and mTOR-independent autophagy inducers ameliorate toxicity of polyglutamine-expanded huntingtin and related proteinopathies. Cell Death Differ 16: 46-56, 2009.

49. Clarke PG: Developmental cell death: Morphological diversity and multiple mechanisms. Anat Embryol (Berl) 181: 195-213, 1990.

50. Larsen KE and Sulzer D: Autophagy in neurons: A review. Histol Histopathol 17: 897-908, 2002.

51. Kabeya Y, Mizushima N, Ueno T, Yamamoto A, Kirisako T, Noda T, Kominami E, Ohsumi Y and Yoshimori T: LC3, a mammalian homologue of yeast Apg8p, is localized in autophagosome membranes after processing. EMBO J 19: 5720-5728, 2000.

52. Kitanaka C and Kuchino Y: Caspase-independent programmed cell death with necrotic morphology. Cell Death Differ 6: 508-515, 1999.

53. Scarlatti F, Granata R, Meijer AJ and Codogno P: Does autophagy have a license to kill mammalian cells? Cell Death Differ 16 12-20, 2009.

54. Liang XH, Jackson S, Seaman M, Brown K, Kempkes B Hibshoosh H and Levine B: Induction of autophagy and inhibition of tumorigenesis by Beclin 1. Nature 402: 672-676, 1999.

55. Kanno H, Ozawa H, Sekiguchi A and Itoi E: Spinal cord injury induces upregulation of Beclin 1 and promotes autophagic cell death. Neurobiol Dis 33: 143-148, 2009.

56. Pais TF, Szegó ÉM, Marques O, Miller-Fleming L, Antas P, Guerreiro P, de Oliveira RM, Kasapoglu B and Outeiro TF: The NAD-dependent deacetylase sirtuin 2 is a suppressor of microglial activation and brain inflammation. EMBO J 32: 2603-2616, 2013.

57. Green DR, Galluzzi L and Kroemer G: Mitochondria and the autophagy-inflammation-cell death axis in organismal aging. Science 333: 1109-1112, 2011 